\title{
Economic growth and height of youth: a panel data analysis on 27 provinces in China, 1985-2014
}

\author{
Ke Hong YU \\ Zhejiang University \\ Xiao Mei Gan \\ Zhejiang University \\ Xu WEN ( $\nabla$ wenxu@zju.edu.cn ) \\ Zhejiang University https://orcid.org/0000-0003-3658-6368
}

Research article

Keywords: Economic growth; Height; Association

Posted Date: August 12th, 2019

DOI: https://doi.org/10.21203/rs.2.12586/v1

License: (ㄷ) (i) This work is licensed under a Creative Commons Attribution 4.0 International License. Read Full License 


\section{Abstract}

Background: This study aimed to empirically examine the influence of China's macroeconomic development on the height of Chinese youth in the past 30 years, using provincial panel data collected from more than one million children. Methods: Panel data from seven longitudinal surveys (1985, 1991, 1995, $2000,2005,2010$, and 2014) of the Chinese National Surveys on Students' Constitution and Health, including students aged 7-22 years from 27 provinces, were utilized for data analysis. Fixed-effects models were used to estimate the association between economic growth and height. Results: For every $1 \%$ increase in per capita disposable income (PCDI), the average height of students significantly increased by approximately $0.009 \%$. Stated another way, this implies that a doubling of income is associated with $0.9 \%$ increase in height, which is significant for height. The coefficient of PCDI in the last decade is higher than that of in the early two decades. The average height of boys was approximately $3.9 \%$ higher than that of girls. The average height difference between high and low ages in the sample was $1.9 \%$. The impact of policies on students' height was extremely small and may have little practical significance. Conclusion: China's economic growth has a significant positive effect on the height of urban Chinese students without stagnation.

\section{Background}

Although height is highly heritable, it is also closely related to environmental factors such as socioeconomic status, nutrition and exposure to infections, and those factors depending on macro-economy development[1-3]. Studies have focus on the influence of economic development and social changes on height. The data of 364,538 women, aged between 25 and 49 years, from 54 low- to middle-income countries between 1994 and 2008 were collected and analyzed. A positive association between wealth and height in $96 \%$ (52/54) of the countries was found囚and fourteen countries in Africa experienced a decrease in height, where nutritional and environmental circumstances were worse than those of other countries[4]. Results also revealed that urban children in most low- and middle-income countries who received better education, health care, and infrastructure construction were taller and heavier than their rural counterparts[5-7]. Moreover, the average height of students living in large urban centers was higher than that of students living in small urban centers in Poland [8]. These results indicated that the macro-economy has a non-negligible impact on the height of residents.

Changes in the macro-economy also exerted a significant influence on children's height[9-14]. An attenuation of growth was suggested during the Great Depression, where growth was moderate, i.e., 1-2 cm, after the mid-20th century for White and Black Americans[12]. Findings revealed that macroeconomic development has an impact on height. However, determining the extent of the influence of macro-economy on height remain an interesting research focus.

The dramatic increase in height in Europe during the late 19th century was closely associated with the industrial revolution[15, 16].This effect can be attributed to the general improvement of living standards, improved nutrition and health care, reduced child mortality, and urbanization [11]. Meanwhile, China has implemented its reform and opening up policy since the end of the 20th century. Similarly, China's economy has developed by leaps and bounds over the past 30 years, so, it is worth studying whether the rapid development of China's economy in recent decades would bring changes in the height of youth. In addition, most studies on the association between macroeconomic factors and height are cross-sectional studies[4, 7, 12, 14], whereas longitudinal studies are limited. Therefore, the present study aims to empirically evaluate how powerful the impact of China's macroeconomic development on the height of Chinese youth is, using provincial panel data collected from more than one million children in the past 30 years.

\section{Method \\ Data}

\section{Height data}

Data were derived from the report of 1985, 1991, 1995, 2000, 2005, 2010, and 2014 Chinese National Surveys on Students' Constitution and Health[1723]. The CNSSCH is a series of surveys conducted by the Ministries of Education, Health, Science and Technology, the State Ethnic Affairs Commission, and the State Sports General Administration of the People's Republic of China. This study included only subjects of Han ethnicity, who account for $92 \%$ of the total Chinese population. The respondents came from 27 out of 31 provinces of China, excluding Hainan and Chongqing, both of which were founded after 1985. Qinghai and the Tibet autonomous region were also excluded because the former missed the 1995 survey, whereas the latter did not participate in nearly all surveys. Each province had equal sample sizes from three socioeconomic classes (i.e., "upper," "moderate," and "low") at the regional level. The participants were students aged 7-22 years from primary to college levels, who were selected from the same areas in each province from 1985-2014. Respondents were selected by stratified cluster sampling from certain classes, and the clusters were randomly selected from each grade in selected schools. Table 1 presents the sample sizes at each examination period. Metal column height measuring stands $(200 \mathrm{~cm}$ with a $0.1-\mathrm{cm}$ precision) were used to measure each respondent's stature without shoes on.

\section{Socioeconomic data}

The data of per capita disposable income (PCDI) were derived from the respective statistical yearbooks of China's provinces (1985, 1991, 1995, 2000, 2005, 2010, and 2014) and the statistical database of the Chinese economic network [24].

\section{Variables}


To overcome heteroscedasticity and enhance the stationarity of data, we took the logarithm of all variables[25]. The dependent variable, Inheight, is the log of the student's height. The core independent variable, PCDI, represents the indicators of the economy. The control variables are sex, age, and policy. Gender and policy are dummy variables. Three vital policies, regulations, and opinions on strengthening students' physical fitness, which were issued by the Central Government and the Ministry of Education, were selected. They are named P90, P97, and P07, which refer to the regulations on school sports as issued by the State Education Committee of the People's Republic of China on 12 March 1990. The implementation plan for the physical education examination for junior high school graduates was issued by the State Education Commission on 16 November 1997. Opinions on advocating teenagers to participate in sports and reinforce physical fitness were issued by the Central Committee of the Communist Party of China and State Council on 7 May, 2007.

\section{Estimation approach}

Panel econometric model was employed to estimate the association between students' height and PCDI and other factors, using height as the dependent variable and PCDI as a key independent variable. To reduce endogeneity, several control variables were introduced. To overcome heteroscedasticity and enhance the stationarity of data, we took the logarithm of all variables. Stata12.0 software was used to conduct the static model empirical analysis.

$\operatorname{lny}_{i t}=a_{i}+\beta_{1} \ln P C D I_{i t}+\beta_{2}$ sex $+\beta_{3}$ age $+\beta_{4} P 90+\beta_{5} P 97+\beta_{6} P 07+\varepsilon$ it

where Inyit is log of the height status in province i at time t, InPCDI is the log of the ecnomic level of province i, sex, age,P90,P97and P07are control variables that are expected to relate height, sex is dummy variable,age is a numerical variable consisting of 7 to 22 . P90,P97and P07 refer to the regulations which are dummy variables, and $\varepsilon$ it is the error term. Equation used the fixed effect regression which controls for time-invariant characteristics, such as climatic conditions and unmeasured cultural factors, and any time-varying differences common to all provinces.

\section{Results}

\section{Trends in height}

The average height of male and female students increased steadily from 1985-2014 without any tendency to plateau (Figures 1 and 2, respectively). The research focuses on 7-, 13-, 16-, and19-year-old students as first-grade ages in the primary, junior high school, senior high school, and university levels, respectively. Among all ages, the increment in the height of males was largely pronounced at puberty(at $13 y e a r s$ old), with an increase of $9.3 \mathrm{~cm}$ in three decades. In contrast, among all ages, the increment of the height in females was largely pronounced at childhood(at 7 years old), with an increase of 5.87 $\mathrm{cm}$ in three decades. The second largest increment of height in males was $6.46 \mathrm{~cm}$ at 7years old relative to $4.66 \mathrm{~cm}$ in females at 13 years old.

\section{Trends in PCDI}

Figure 2 presents the socioeconomic changes in China between 1985 and 2014. As can be seen, urban PCDI increased from 739 to $28,843 y u a n$ during this period.

\section{Empirical analysis}

On the basis of the natural logarithm of each variable, the robust command was used to correct the standard error with white heteroscedasticity, so as to make the result more robust. All following regressions eliminated the outliers.

Table2 present the estimated results of the fixed effects models which is the test of the association between China's economic growth and the height of urban students after controlling for other variables, such as gender, age, and policy. A significant positive coefficient of 0.009 was found in this model. Given the log-log specification, this coefficient represented the elasticity of height with respect to PCDI: an increase of $1 \%$ in PCDI occurred with an increase in average height by approximately $0.009 \%$. This indicated that, for every $1 \%$ increase in PCDI, the average height of youth in China increased by approximately $0.009 \%$ given that other factors remain unchanged. Stated another way, this implies that a doubling of income is associated with $0.9 \%$ increase in height, which is significant for height. This finding reveals that economic growth may exert a promoting effect on students' height. The coefficient of sex is 0.039 , which is highly significant at the statistical level of $1 \%$. The coefficient can be explained as the average height of the male sample, which is approximately $3.9 \%$ higher than the average height of the female sample. The coefficient of age is 0.019 , which passes the significance level of $1 \%$. This coefficient can be interpreted as the average height difference between adjacent ages of the sample students at $1.9 \%$. The impact of policies in 1990 and 1997 on students' height was negative and highly significant. However, the coefficient value is extremely small and may have little practical significance.

As shown in Figure 1, 2005 is the turning point not only of China's macro-economy, but also of a new round of healthy economic growth. Therefore, to further explore trends of association between PCDI and students' height, the model was estimated during two periods, namely, 1985-2005 and 20052014,as shown in Columns (3) and (4), respectively. The coefficient of InPCDI in Column (3) is 0.009, which is highly significant at the $1 \%$ statistical level. This finding may indicate that the economic growth from 1985-2005 has a significant promoting effect on the height of Chinese youth. 
As shown in Column (4), the elasticity of students' height is 0.011 , which is highly significant. The coefficient is higher than that of in the early two decades. This finding may indicate that the Chinese economy has had additional positive effects on the height growth of children and adolescents from 2005 to 2014. In summary, the results show that the positive effect of the Chinese economy on students' height may gradually increase without any tendency to plateau.

\section{Discussion}

Using provincial-level 5-year interval panel data of 27provincesfrom 1985-2014, the current study reveals that economic growth has a significant positive effect on the height growth of youth. Data also show a linear relationship between economic growth and height of youth, suggesting an average height increase with continued increase in PCDI without any stagnation. Moreover, the study also indicates that the effect of economic growth on students' height in the past ten years is greater than that in the previous 20 years. In fact, numerous studies reported a positive association between economic status and healthy output in both developed and developing countries [4, 6, 7]. Increase in height growth entered a period of rapid growth in the past 30 years.[26-28]. From 1995-2005, the height increments of urban male and female students aged 7-18 years in China were 2.0 and $1.3 \mathrm{~cm}$, respectively[27]. From 20052014, the height increments of the urban male and female aged 7-18 in China were 2.0 and $1.7 \mathrm{~cm}$, respectively[26].

Several reasons may explain the mechanism of economic influence on the height of children and adolescents. First, China's economy experienced unprecedented growth in the past 30 years. The country's rapid economic development has also brought about tremendous changes in the dietary structure and habits of the Chinese people[29]. In 1993, the rationing system was abolished, open markets became dominant, and a modern food system began to take shape[30], which improved crop and poultry productivity[31] and dramatically enriched the diet of the Chinese people. Entering the 21st century, China's economy achieved a new round of development. With the improvement of living standard and of health consciousness, people gradually prioritized healthy foods, such as milk, fish, and shrimp [32]. These are rich in high-grade protein and calcium essential for bone development [33]. The increase in high-quality protein and calcium intake, which is vital to bone development, significantly increased Chinese children's average height. Moreover, China's expenditure on healthcare significantly increased over the last 30 years, which accelerated the development of public health in the country. The health of youth definitely benefited from the regular examination of physical development, iron deficiency anemia, and other common diseases. Physical assessments for the prevention and treatment of malnutrition, acalcerosis in children, and obesity were also conducted regularly[34]. The implementation of public health projects in China enhanced Chinese residents' health awareness and health knowledge and encouraged them to develop healthy habits[35, 36].In addition, driven by the rapid economic development, the Chinese people's educational level has significantly improved as well. A number of studies showed that parents' social economic status, including education level, has a significantly positive influence on the height of children and adolescents [37-39].

\section{Limitations and strengths}

Concerning the methodological issues, our estimations maybe have endogeneity issues, such as omitted variable problems. Another limitation is that our study focuses only on urban youth. Future studies should pay increased attention to rural youth and make a comparison between the two populations to gain a deeper analysis of the physical conditions of the Chinese youth.

Despite these limitations, the panel data in this paper included time series and cross-section data, which were collected across 30 years from 27 provinces in China from over one million students. In addition, the panel model can longitudinally analyze the trend of the association between economy and height, and evaluate how powerful the impact of macro-economy on height of youth is. This perspective can provide a comprehensive and targeted analysis and is a critical step as China moves toward its goal of Healthy China 2030[40].

\section{Conclusion}

In summary, this study provides evidence for the association between macro-economic growth and height of Chinese youth. China's economic growth has shown positive influence on the height of Chinese youth without any trend of stagnation

\section{Abbreviations}

PCDI: Per Capita Disposable Income; CNSSCH: Chinese National Surveys on Students' Constitution and Health; P90:Regulations on school sports as issued by the State Education Committee of the People's Republic of China on 12 March 1990;P97: The implementation plan for the physical education examination for junior high school graduates issued by the State Education Commission on 16 November 1997; P07: Opinions on advocating teenagers to participate in sports and reinforce physical fitness issued by the Central Committee of the Communist Party of China and State Council on 7 May, 2007.

\section{Declarations}

\section{Acknowledgments}

We thank all team members and participants for the Chinese National Surveys on Students' Constitution and Health (1985-2014).

\section{Authors' contributions}


All authors read and approved the final manuscript. KY, XG, and XW designed the study, collected the data, participated in statistical analysis, and drafted the manuscript. XG played a role in data collection and data analysis.

\section{Availability of data and materials}

The data support this study came from the reports of Chinese National Surveys on Students' Constitution and Health which was conducted by the by the Ministry of Education, Ministry of Science and Technology, National Health Commission, National Ethnic Affairs Commission, and the State Sports General Administration of the People's Republic of China. The raw data is confidential and not publicly available. Data may be shared with researchers obtaining permissions from the Ministry of Education of the People's Republic of China.

\section{Funding}

This study is supported by National Social Science Foundation key program project囚17ATY009囚. The funder had no role in the study design, data collection, data analysis, data interpretation, writing of the paper, or the decision to submit the paper for publication.

\section{Ethics approval and consent to participate}

Data were retrieved from the reports of Chinese National Surveys on Students Constitution and Health (CNSSCH). The CNSSCH was conducted by the by the Ministry of Education, Ministry of Science and Technology, National Health Commission, National Ethnic Affairs Commission, and the State Sports General Administration of the People's Republic of China. The authors did not collect the raw data but only do the data analysis. This study was approved by the Ethics Committee of College of Education in Zhejiang University.

\section{Competing interests}

The authors declare that they have no competing interests.

\section{Consent for publication}

Not Applicable

\section{References}

1.Crimmins, E. M. and C. E. Finch, Infection, inflammation, height, and longevity. Proceedings of the National Academy of Sciences of the United States of America, 2006. 103(2): p. 498-503.

2.Ascenso, A., et al., Physical activity and cardiorespiratory fitness, but not sedentary behavior, are associated with carotid intima-media thickness in obese adolescents. European Journal of Pediatrics, 2015. 175(3): p. 391-398.

3.Steckel, R. H., Heights and human welfare: Recent developments and new directions. Explorations in Economic History, 2009. 46(1): p. 1-23.

4.Subramanian, S. V., E. Ozaltin, and J. E. Finlay, Height of Nations: A Socioeconomic Analysis of Cohort Differences and Patterns among Women in 54 Low- to Middle-Income Countries. PLoS ONE, 2011. 6: p. e18962.

5.Constitution, C.s.N. G. O. S., H. Survey, and C. Ji, Dynamic analyses on physical growth and development status in Chinese students. Zhonghua yu fang yi xue za zhi [Chinese journal of preventive medicine], 2002. 36(2): p. 77.

6.Hui, L. I., et al., Physical Growth of Children in Urban, Suburban and Rural Mainland China: A Study of 20 Years' Change. Biomedical \& Environmental Sciences, 2011. 24(1): p. 1-11.

7.Paciorek, C. J., et al., Children's height and weight in rural and urban populations in low-income and middle-income countries: a systematic analysis of population-representative data. Lancet Global Health, 2013. 1(5): p. e300-e309.

8.Monika, K. and U. A. Wioleta, The relationship of Polish students' height, weight and BMI with some socioeconomic variables. J Biosoc Sci, 2010. 42(5): p. 643-652.

9.Dubrova, Y. E., et al., Secular growth trend in two generations of the Russian population. Human Biology, 1995. 67(5): p. $755-767$.

10.Fedorov, L., et al., Socioeconomic Determinants of Children\& $\# x 2019$; s Health in Russia: A Longitudinal Study. Economic Development and Cultural Change, 2005. 53(2): p. 479-500.

11.Grasgruber, P., et al., The role of nutrition and genetics as key determinants of the positive height trend. Economics \& Human Biology, 2014. 15: p. 81100. 
12.Komlos, J. and B. E. Lauderdale, The mysterious trend in American heights in the 20th century. Annals of Human Biology, 2007. 34(2): p. 206.

13.Schmidt, I. M., M. H. Jørgensen, and K. F. Michaelsen, Height of conscripts in Europe: is postneonatal mortality a predictor? Annals of Human Biology, 1995. 22(1): p. 57-67.

14.Webb, E. A., et al., Estimation of secular trends in adult height, and childhood socioeconomic circumstances in three Eastern European populations. Economics \& Human Biology, 2008. 6(2): p. 228-236.

15.Baten, J. and M. Blum, Growing Tall but Unequal: New Findings and New Background Evidence on Anthropometric Welfare in 156 Countries, $1810-$ 1989. Economic History of Developing Regions, 2012. 27(sup1): p. S66-S85.

16.Hatton, T. J. and B. E. Bray, Long run trends in the heights of European men, 19th-20th centuries. Economics \& Human Biology, 2010. 8(3): p. 405-413. 17.CNSSCH Association Report on the 1985th National Survey on Students' Constitution and Health. 1987, Beijing: People's Educational Publication. 18.CNSSCH Association Report on the 1991th National Survey on Students' Constitution and Health. 1993, Beijing: Beijing Technical and Science Press. 19.CNSSCH Association Report on the 1995th National Survey on Students' Constitution and Health. 1997, Changchun: Jilin Technical and Science Publication.

20.CNSSCH Association Report on the 2000th National Survey on Students' Constitution and Health. 2002, Beijing: China College \& University Press. 21.CNSSCH Association Report on the 2005th National Survey on Students' Constitution and Health. 2007, Beijing: China College \& University Press. 22.CNSSCH Association Report on the 2010th National Survey on Students' Constitution and Health. 2012, Beijing: China College \& University Press. 23. CNSSCH Association Report on the 2014th National Survey on Students' Constitution and Health. 2016, Beijing: China College \& University Press. 24.Statistical Yearbook of China's Provinces (1985, 1995, 2000, 2005, 2010 and 2014), http://data.cnki.net/Yearbook. 25.M.Wooldridge, J., Introductory Econometrics: A Modern Approach (5th edition). 2014, Beijing: tsinghua university press.

26.Gao, D., et al., Analysis on the change trend of height and weight of middle and primary school students in China from 2005 to 2014 . Chinese journal of school health, 2018(2).

27.Ma, J., et al., Secular growth trends in height and weight of Chinese children aged 7 to 18 year-old from 1985 to 2005 . Journal of Peking University (Health Sciences), 2010. 42(3): p. 318-322.

28.Zong, X. N., et al., Socioeconomic development and secular trend in height in China. Economics \& Human Biology, 2015. 19: p. 258-264.

29.Zhai, F. Y., et al., Dynamics of the Chinese diet and the role of urbanicity, 1991-2011. Obesity Reviews An Official Journal of the International Association for the Study of Obesity, 2013. 15(S1): p. 16-26.

30.Yang, Z. P., et al., Analysis of physical fitness and related factors of Chinese han students aged 13-18 in 2014. 2018. 52(8): p. 809.

31.Wang, H., et al., Producing and Procuring Horticultural Crops with Chinese Characteristics: The Case of Northern China. World Development, 2009. 37(11): p. 1791-1801.

32.Delgado, C. L., Rising consumption of meat and milk in developing countries has created a new food revolution. Journal of Nutrition, 2003. 133(2): p. 3907S.

33.Dawson-Hughes, B., Interaction of dietary calcium and protein in bone health in humans. Journal of Nutrition, 2003. 133(3): p. 852S-854S.

34.Dongxu, W. and S. Donald, The implementation and effectiveness of school-based nutrition promotion programmes using a health-promoting schools approach: a systematic review. Public Health Nutrition, 2013. 16(6): p. 1082-1100.

35.Ling, R. E., et al., Emerging issues in public health: a perspective on China's healthcare system. Public Health, 2011. 125(1): p. 9-14.

36.Smith, R. D., et al., Global Public Goods for Health: Health economic and public health perspectives. General Information, $2003.13(5)$ : p. 501-501.

37.Murasko, J. E., Associations between household income, height, and BMI in contemporary US schoolchildren. Economics \& Human Biology, 2013. 11(2): p. 185-196.

38.Suchomlinov, A. and J. Tutkuviene, FACTORS ASSOCIATED WITH CHILDREN'S HEIGHT AND BODY MASS INDEX IN LITHUANIA, 1990-2008. J Biosoc Sci, 2016. 48(4): p. 502-529.

39.Tucker-Seeley, R. D. and S. V. Subramanian, Childhood circumstances and height among older adults in the United States $\mathbb{\otimes}$. Economics \& Human Biology, 2011. 9(2): p. 194-202. 
40.China, G. A.o.S.o. National FitnessGuide.http://www.sport.gov.cn/n317/n10506/c819331/content.html;: 2017.

\section{Tables}

Table 1. Sample Sizes at Each Examination Period in CNSSCHA (Aged 7-22years), 1985-2014

\begin{tabular}{|c|c|c|c|c|c|c|c|c|c|c|c|c|c|c|}
\hline & Male & & & & & & & Female & & & & & & \\
\hline & 1985 & 1991 & 1995 & 2000 & 2005 & 2010 & 2014 & 1985 & 1991 & 1995 & 2000 & 2005 & 2010 & 2014 \\
\hline 7 & 8560 & 2933 & 4401 & 3051 & 4935 & 4486 & 4464 & 8559 & 2925 & 4400 & 4512 & 4860 & 4481 & 4480 \\
\hline 8 & 8561 & 2999 & 4398 & 4446 & 4934 & 4485 & 4489 & 8561 & 2977 & 4406 & 4533 & 4862 & 4469 & 4487 \\
\hline 9 & 8557 & 2959 & 4397 & 4546 & 4945 & 4481 & 4478 & 8561 & 2951 & 4402 & 4494 & 4892 & 4490 & 4490 \\
\hline 10 & 8557 & 2932 & 4390 & 4571 & 4916 & 4490 & 4485 & 8559 & 2942 & 4402 & 4657 & 4932 & 4487 & 4488 \\
\hline 11 & 8561 & 2965 & 4396 & 4587 & 5051 & 4500 & 4487 & 8559 & 2935 & 4413 & 4498 & 4894 & 4496 & 4474 \\
\hline 12 & 8558 & 2957 & 4398 & 4524 & 4917 & 4483 & 4479 & 8557 & 2875 & 4397 & 4518 & 4785 & 4484 & 4477 \\
\hline 13 & 8558 & 2906 & 4394 & 4523 & 4914 & 4487 & 4487 & 8558 & 2933 & 4395 & 4530 & 4925 & 4487 & 4495 \\
\hline 14 & 8560 & 2948 & 4403 & 4546 & 4852 & 4489 & 4487 & 8561 & 2931 & 4383 & 4513 & 4859 & 4494 & 4485 \\
\hline 15 & 8556 & 2952 & 4403 & 4561 & 4979 & 4489 & 4482 & 8556 & 2924 & 4394 & 4516 & 4935 & 4482 & 4489 \\
\hline 16 & 8559 & 2936 & 4343 & 4551 & 4892 & 4476 & 4481 & 8557 & 2911 & 4396 & 4519 & 4916 & 4454 & 4493 \\
\hline 17 & 8532 & 2936 & 4395 & 4507 & 4919 & 4488 & 4494 & 8537 & 2910 & 4403 & 4524 & 4857 & 4485 & 4490 \\
\hline 18 & 8324 & 2968 & 4335 & 4549 & 4979 & 4476 & 4289 & 8159 & 2933 & 4365 & 4632 & 5047 & 4435 & 4289 \\
\hline 19 & 5516 & 2937 & 2850 & 3302 & 3777 & 2971 & 2973 & 5551 & 2988 & 2863 & 3449 & 3938 & 2996 & 2997 \\
\hline 20 & 5593 & 2953 & 2876 & 3181 & 3741 & 2975 & 2970 & 5580 & 2968 & 2880 & 3306 & 3905 & 2982 & 2988 \\
\hline 21 & 5592 & 2770 & 2875 & 3187 & 3744 & 2972 & 2989 & 5462 & 2751 & 2879 & 2958 & 3752 & 2986 & 2987 \\
\hline 22 & 4332 & 2955 & 2829 & 2718 & 3327 & 2915 & 2865 & 3335 & 2685 & 2737 & 2555 & 3390 & 2917 & 2881 \\
\hline Total & 123,476 & 47,006 & 64,083 & 65,350 & 73,822 & 65,663 & 65,399 & 122,212 & 46,539 & 64,115 & 66,714 & 73,749 & 65,625 & 65,490 \\
\hline
\end{tabular}

Table 2 Econometric Estimates of the Association between PCDI and Height 


(1) (2) (3) (4)

\begin{tabular}{|c|c|c|c|c|}
\hline & Inheight & Inheight & Inheight & Inheight \\
\hline \multirow[t]{2}{*}{ InPCDI } & $0.009 * \star \star$ & 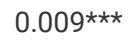 & $0.009 * \star \star$ & $0.011^{\star \star *}$ \\
\hline & $(50.67)$ & $(44.36)$ & (43.98) & (15.85) \\
\hline \multirow[t]{2}{*}{ sex } & & $0.039 * \star \star$ & $0.037 * \star \star$ & $0.043^{\star * *}$ \\
\hline & & $(12.20)$ & $(11.67)$ & $(13.46)$ \\
\hline \multirow[t]{2}{*}{ age } & & $0.019 * \star *$ & $0.019 * \star \star$ & $0.017 * * \star$ \\
\hline & & $(48.29)$ & (49.55) & $(44.83)$ \\
\hline \multirow[t]{2}{*}{ p90 } & & $-0.003^{\star * \star}$ & $-0.003^{\star * *}$ & \\
\hline & & $(-12.64)$ & $(-12.51)$ & \\
\hline \multirow[t]{2}{*}{ p97 } & & $-0.002^{\star \star \star}$ & $-0.002^{\star \star \star}$ & \\
\hline & & $(-5.49)$ & $(-5.35)$ & \\
\hline \multirow[t]{2}{*}{ p07 } & & 0.000 & & \\
\hline & & $(1.11)$ & & \\
\hline \multirow[t]{2}{*}{ _cons } & $4.955^{\star \star \star}$ & 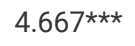 & $4.661^{\star \star \star}$ & $4.661^{\star \star \star}$ \\
\hline & (1094.14) & (709.13) & (712.92) & (482.88) \\
\hline $\mathrm{R} 2$ & 0.60 & 0.60 & 0.49 & 0.23 \\
\hline$P$ & 0.000 & 0.000 & 0.000 & 0.000 \\
\hline $\mathrm{N}$ & 6047 & 6047 & 4319 & 1728 \\
\hline
\end{tabular}

t statistics in parentheses

The White(1980) robust regression

$=" \star p<0.1$

$\star * p<0.05$

$\star \star \star ~ p<0.01 "$

\section{Figures}

\section{Male}

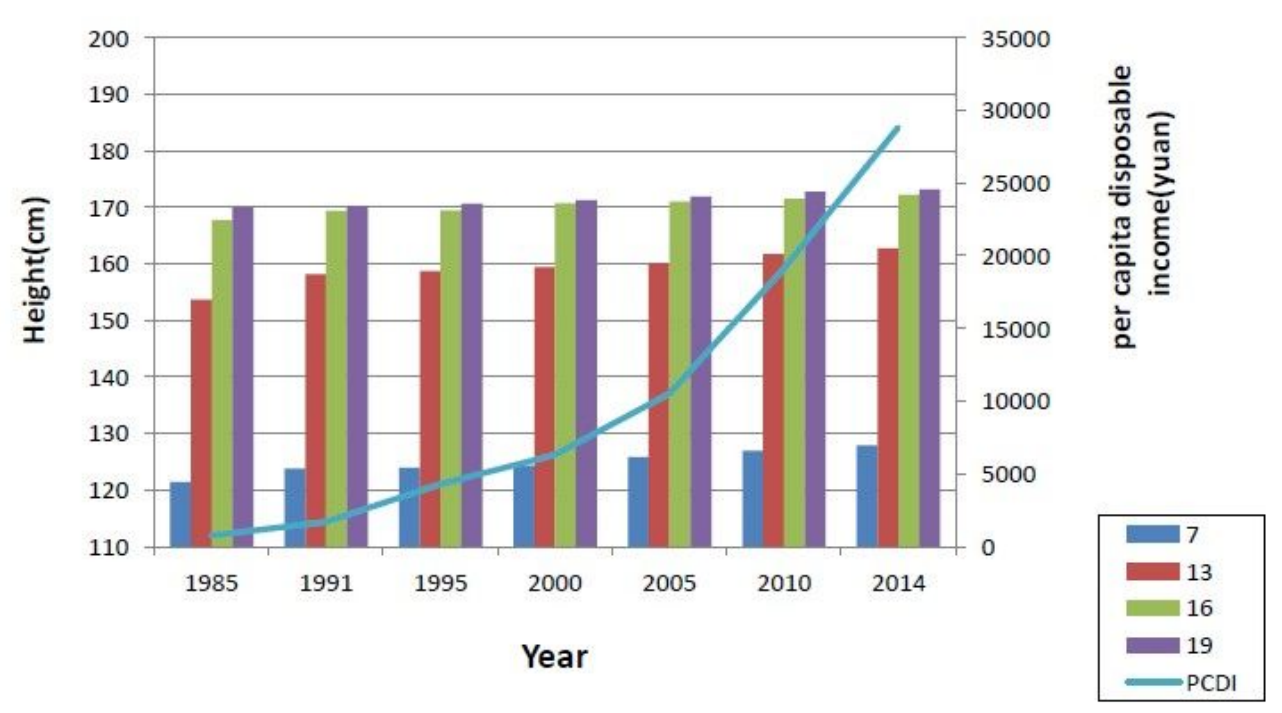


Figure 1

Trends in Height and PCDI in Males

Female

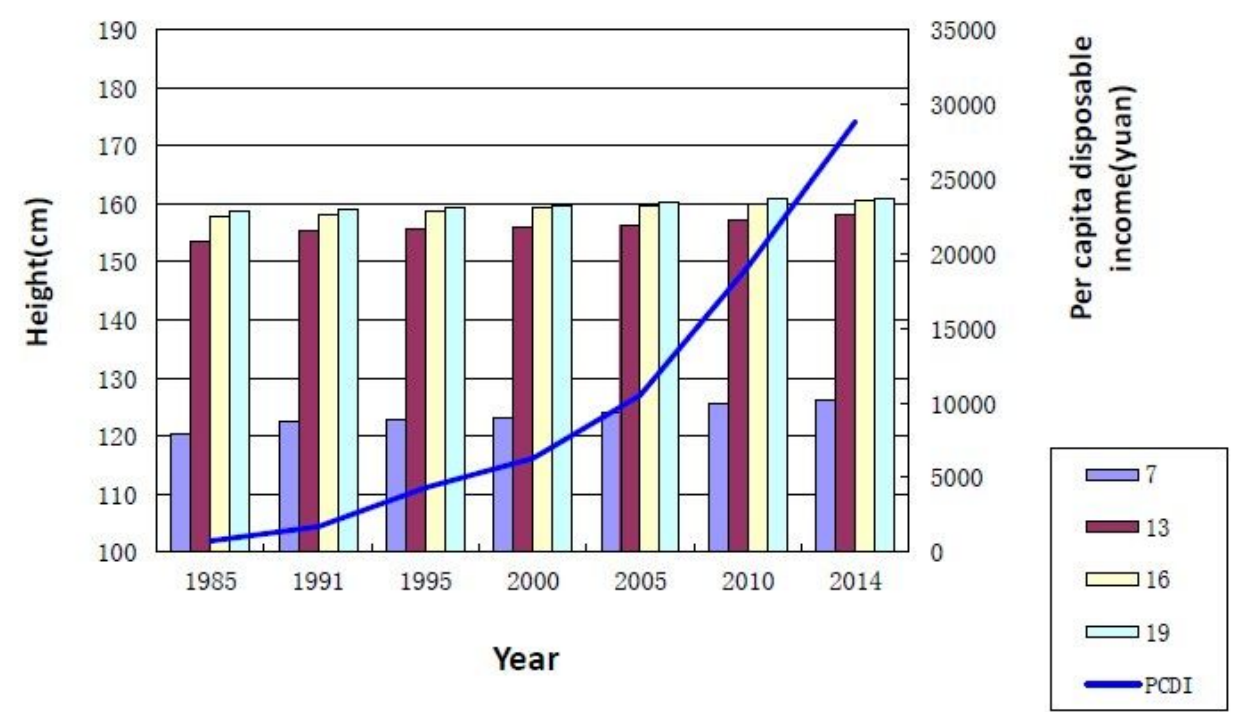

Figure 2

Trends in Height and PCDI in Females 